\title{
https://doi.org/10.46813/2021-133-056 \\ HETEROSTRUCTURED ORGANIC SCINTILLATORS WITH A HIGH PULSE-SHAPE DISCRIMINATION CAPABILITY FOR RADIOECOLOGY PROBLEMS
}

\author{
I.F. Khromiuk ${ }^{1 *}$, N.Z. Galunov ${ }^{1,2}$, N.L. Karavaeva ${ }^{1}$, A.V. Krech ${ }^{1}$, Ya.I. Polupan ${ }^{1}$, \\ O.A. Tarasenko ${ }^{1}$ \\ ${ }^{1}$ Institute for Scintillation Materials NAS of Ukraine, Kharkiv, Ukraine; \\ ${ }^{2}$ V.N. Karazin Kharkiv National University, Kharkiv, Ukraine \\ *E-mail: ikhromiuk@gmail.com
}

Studies of the relative Light output and optical transmission of organic composite scintillators with different grain sizes were performed. The research results showed that for samples with grains $0.06 \ldots 0.3 \mathrm{~mm}$ in size, in contrast to the samples with larger grains, the relative light output and optical transmission are lower.

PACS: $32.50 .+\mathrm{d} ; 78.60 .-\mathrm{b} ; 87.53$

\section{INTRODUCTION}

The detection of low-intensity ionizing radiation fluxes is very relevant. It is important in modern environmental, biological, medical, geological problems. It used to prevent the unauthorized transportation of radioactive materials, to eliminate the consequences of human-made disasters.

The product of dose value of radiation absorbed by the body on the value of the radiation weight factor $\omega_{R}$ is the quantitative characteristic that determines the influence of ionizing radiation on the human body. The weight factor determines the long-term effects (the possibility of serious diseases such as oncology) of a chronic dose of low intensity.

The main part of the neutron energy spectrum of natural radionuclides or possible radiation around nuclear power plants, which occur due to failure, has an energy $E_{n} \leq 2 \mathrm{MeV}$. If for photons of gamma radiation $\omega_{R}=1$, then for alpha particles, fast neutrons with energies $E_{n} \leq 2 \mathrm{MeV}$ and nuclei of heavy ionized atoms, the value $\omega_{R}=20$ [1]. It means that if the device accurately counts the number of registered events without dividing them by their nature, then such information does not correspond to the real situation, and its use can be dangerous.

Good neutron spectrometry requires substances with high hydrogen content. Therefore, organic molecular materials become optimal. Due to $A$ and $Z$ small values for carbon and hydrogen nuclei, these materials with a density close to $1 \mathrm{~g} / \mathrm{cm}^{3}$ have negligible backscattering for charged particles. It increases the efficiency and stability of the detection of charged particles in comparison with inorganic scintillators. Unfortunately, the technology of obtaining organic single crystals imposes strict limits on their maximum size and shape; it is quite expensive. Liquid scintillators are toxic and flammable [2].

To solve this problem, we propose to study more promising newly created materials. It is heterostructured scintillation materials of new types [2 - 6]. They are organic scintillators containing single-crystal grains. When we are sintering the grains by hot pressing, we obtain a polycrystal (Van-der-Waltz ceramics). The introduction of the grains into a transparent gel compo- sition gives a composite scintillator. Ionizing radiations generate two types of luminescent response. They are prompt and delayed radioluminescence. Ionizing radiation with large values of specific energy losses $(d E / d x)$ (recoil nuclei, alpha-particles, low-energy electrons) generates a scintillation pulse with a large contribution of a slow component. The radiations with a small $d E / d x$ (e.g., photons, X-rays, photons of gamma radiation, electrons of medium and high energies) generate a scintillation pulse whose slow component contribution is small. The slow component arises as a result of the process of triplet-triplet $(T-T)$ annihilation of localized triplet molecular excitons (in the future $T$-states) $[2,7,8]$. In the presence of efficient diffusion transport of $T$-states, they can be localized on neighbouring molecules, i.e., to approach each other at a distance where the exchangeresonance mechanism of their interaction becomes possible. The efficiency of transport of $T$-states in a particular scintillation material and its ability to separate signals from radiation with different $d E / d x$ determine the slow component intensity. For classical organic single crystals and liquids, their ability to separate signals from radiation with different $d E / d x$ is a well-known experimental fact. It is the pulse shape discrimination (PSD) capability. The features of transport and recombination of $T$-states in such materials are also well studied. Such information about heterostructured materials, where the grain size can limit the migration length of $T$-states, is practically absent.

\section{TECHNOLOGICAL ASPECTS OF OBTAINING EXPERIMENTAL SAMPLES}

In works $[7,8]$, we proved the following. It is necessary to conduct comparative analyses of trans-stilbene and $p$-terphenyl PSD capability. Thus, the single crystals and heterostructured scintillators have to be obtained. These results should be comparable to the results obtained for the same material when excited by light in the ultraviolet range (to excite the fission reaction of singlet excitons) and ionizing radiation (alpha-, gamma-, and fast neutrons). An important result of these works is the formulation of the need for comparative studies of the properties of heterostructured materials with different grain sizes. 
The grain size should determine the diffusion conditions for $T$-states, i.e., the conditions for the formation of delayed luminescence and, ultimately, the PSD capability of the material for radiations with different specific energy losses $d E / d x$.

\subsection{SOURCE MATERIALS}

We use commercially available thoroughly purified raw material to produce the scintillation $p$-terphenyl. Unfortunately, trans-stilbene produced by leading companies do not allow us to obtain scintillators with the required high characteristics [9]. Our previous studies (see, e.g., [2]) have identified impurities that limit the characteristics of the material. To produce the transstilbene scintillators, we have to synthesize this raw material.

\subsection{HETEROSTRUCTURED SCINTILLATORS}

To obtain crystal grains of $p$-terphenyl and transstilbene, we used the following approach. By the directional solidification method, we obtained a polycrystalline boule. Then this boule crushed under a layer of liquid nitrogen. We sieved the grains through a calibrated sieve with a mesh size of $3.0 \mathrm{~mm}$. We ground, again and again, the remnants of grains of larger size and undisturbed parts of the single crystal. In the case of crushing a single crystal of trans-stilbene, we repeated the process three times. When grinding a single crystal of $p$ terphenyl, we repeated the process eight times, and each time only $10 \ldots 15 \%$ of the ground material passed through the sieve. To prepare samples containing less than $3 \mathrm{~mm}$ in size, we calibrated grains with sieves with a mesh size of less than $3.0 \mathrm{~mm}$.

\section{EXPERIMENTAL METHODS OF RESEARCH}

\subsection{LIGHT OUTPUT MEASUREMENTS}

The amplitude distribution of the scintillator pulses was measured using an ADC (amplitude-to-digital converter) with the subsequent accumulation and processing of the received information in the computer memory. The relative value of the light signal in this method of measurement can be defined as:

$$
L_{r e l}=\left(\mathrm{J} / J_{r e f}\right) \cdot 100 \% \text {, }
$$

where $J$ is the value of the maximum amplitude of the spectrum of the investigated scintillator; $J_{\text {ref }}$ is the value of the maximum amplitude of the spectrum of the reference scintillator.

Knowing the values of the technical light output of the reference scintillators in photons per $1 \mathrm{MeV}$ makes it possible to obtain the values of the technical light output of the studied samples. The error in determining the light output for this measurement technique does not exceed $5 \%[2,10]$. A ${ }^{137} \mathrm{Cs}$ gamma radiation source $\left(E_{\gamma}=0.662 \mathrm{MeV}\right)$ is used to measure the light yield. Calibration of the measuring path was performed using standard sources of gamma radiation photons, such as. ${ }^{22} \mathrm{Na},{ }^{60} \mathrm{Co},{ }^{137} \mathrm{Cs}$, and ${ }^{152} \mathrm{Eu}$. Alpha-spectra were measured using a ${ }^{239} \mathrm{Pu}$ alpha-particle source.

\subsection{OPTICAL TRANSMITTANCE MEASUREMENT METHOD}

The ratio of the radiation flux $\Phi$ that passes through the substance to the radiation flux $\Phi_{0}$ that incident on its surface we defined as the transmittance T:

$$
T=\left(\frac{\Phi}{\Phi_{0}}\right) \cdot 100 \% \text {. }
$$

The transmittance of samples of heterogeneous scintillators was measured on a spectrophotometer Shimadzu UV-2450. The absolute error in determining the wavelength was $0.4 \mathrm{~nm}$, and the measurement of spectral transmittance coefficients was $0.6 \%$ [11].

The measurements we performed with an integrating sphere. It allows us to collect back most of the scattered light on the spectrophotometer photodetector. The spectrophotometer has two channels. We calibrated the device before measurements. i.e., $100 \%$ has been assigned when the same signal has passed through both channels. Then the sample we place in the path of one of the beams. The sample was tightly pinned to the outer surface of the sphere with a clamp. The measurements were performed relative to air (one channel remained unfilled). This value in formula (2) was taken as $\Phi_{0}=100 \%$.

\section{RESULTS AND DISCUSSION}

\section{1. trans-STILBENE AND $p$-TERPHENYL COMPOSITE SCINTILLATORS LIGHT YIELD}

We studied the scintillation spectra of organic scintillators excited by alpha-particles of the ${ }^{239} \mathrm{Pu}$ source. As a reference, we used a single crystal of trans-stilbene with a diameter of $30 \mathrm{~mm}$ and a thickness of $9 \mathrm{~mm}$ (with light yield $L Y=9.700$ photons/MeV when irradiated by ${ }^{137} \mathrm{Cs}$ source), and a single crystal of $p$-terphenyl with a diameter of 30 and $5 \mathrm{~mm}$ thick ( $L Y=$ 9.800 photons $/ \mathrm{MeV}$ when irradiated by ${ }^{137} \mathrm{Cs}$ source).

Fig. 1 shows the spectra of alpha-scintillations of the reference trans-stilbene single crystal and single-layer composite scintillators of trans-stilbene, and Fig. 2 shows the spectra of alpha-scintillations of the reference sample of single crystal and single-layer composite scintillators of $p$-terphenyl.

It is known that for small fractions of crystal grains, a significant decrease in optical transparency can be observed. It is due to an increase in the number of crystal grain boundaries through which photons of light must pass. It, in turn, can lead to a decrease in the intensity of light passing through the scintillator material. In this regard, it is important to study samples obtained from fractions containing fine grains. For grains of small size, the transport and recombination of $T$-states, which leads to delayed luminescence, have been insufficiently studied. These processes must be able to impose restrictions on the use of scintillators made from small grains. In this case, the probability of the excitation of small grains by ionizing radiation decreases.

Using the alpha-scintillation spectra measurements, we calculate the $L_{r e l}$ values for the samples of singlelayer composite trans-stilbene scintillators. The results are presented in Table 1. The light output of the reference trans-stilbene single crystal was taken as $100 \%$. 


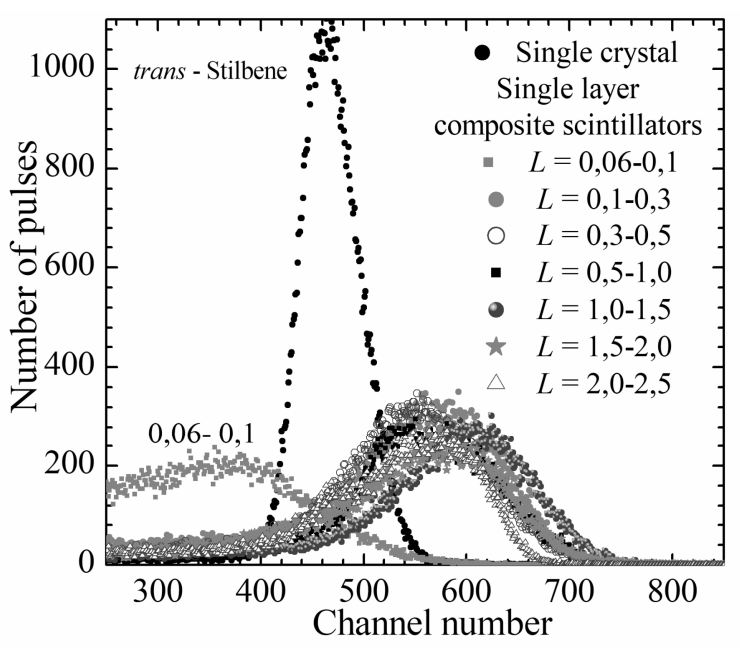

Fig. 1. Spectra of alpha-scintillations of the reference trans-stilbene single crystal and single-layer composite trans-stilbene scintillators (square entrance window size $20 \times 20 \mathrm{~mm}$ ) with different grains size.

The trans-stilbene reference single-crystal diameter is $30 \mathrm{~mm}$ and thickness is $5 \mathrm{~mm}$; the size L of the crys-

talline grains of the composite samples varies

Table 1

Relative light output $L_{\text {rel }}$ of single-layer trans-stilbene composite scintillators

\begin{tabular}{|c|c|l|}
\hline \multicolumn{1}{|c|}{ Sample } & $\begin{array}{c}\text { Grains size } L, \\
\mathrm{~mm}\end{array}$ & $L_{\text {rel }}, \%$ \\
\hline Single crystal & - & 100.0 \\
\hline Composite scintillator & $0.06 \ldots 0.1$ & 76.3 \\
\hline$-/ /-$ & $0.1 \ldots 0.3$ & 127.8 \\
\hline$-/ /-$ & $0.3 \ldots 0.5$ & 119.1 \\
\hline$-/ /-$ & $0.5 \ldots 1.0$ & 118.7 \\
\hline$-/ /-$ & $1.0 \ldots 1.5$ & 134.8 \\
\hline$-/-$ & $1.5 \ldots 2.0$ & 123.9 \\
\hline$-/ /-$ & $2.0 \ldots 2.5$ & 121.7 \\
\hline
\end{tabular}

Table 2 shows the results of $L_{r e l}$ measurements of single-layer composite scintillators containing $p$ terphenyl grains. We took the light output of the reference $p$-terphenyl single crystal as $100 \%$.

Table 2

Relative light output $L_{\text {rel }}$ of single-layer composite scintillators of p-terphenyl

\begin{tabular}{|c|c|c|}
\hline Sample & $\begin{array}{c}\text { Grains size } L, \\
\mathrm{~mm}\end{array}$ & $L_{\text {rel }}, \%$ \\
\hline Single crystal & - & 100.0 \\
\hline Composite scintillator & $0.06 \ldots 0.1$ & 45.7 \\
\hline$-/ /-$ & $0.1 \ldots 0.3$ & 100.7 \\
\hline$-/ /-$ & $0.3 \ldots 0.5$ & 120.6 \\
\hline$-/ /-$ & $0.5 \ldots 1.0$ & 121.1 \\
\hline$-/ /-$ & $1.0 \ldots 1.5$ & 113.3 \\
\hline$-/ /-$ & $1.5 \ldots 2.0$ & 103.8 \\
\hline$-/ /-$ & $2.0 \ldots 2.5$ & 97.5 \\
\hline
\end{tabular}

Also, we carried out similar studies for samples of multilayer composite scintillators of trans-stilbene and $p$-terphenyl. We used grain fractions of $0.1 \ldots 0.3 \mathrm{~mm}$. Fig. 3 shows the alpha-scintillation amplitude spectra of $5 \mathrm{~mm}$ thick trans-stilbene composite scintillators. Table 3 shows $L_{r e l}$ values for trans-stilbene composite scintillators.

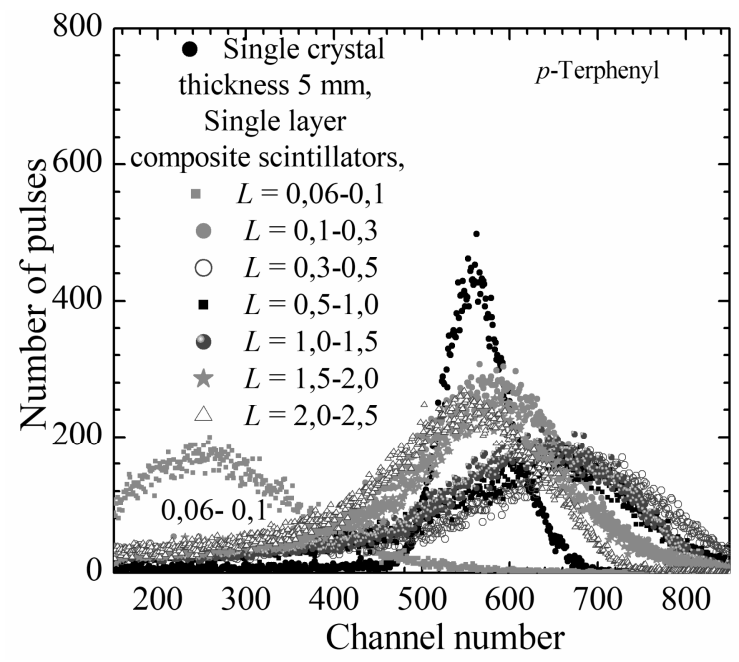

Fig. 2. Spectra of alpha-scintillations of the reference sample of single crystal and single-layer composite scintillators of p-terphenyl (square entrance window size $20 \times 20 \mathrm{~mm}$ ) with different grains $L$.

The reference sample of p-terphenyl has a diameter of 30 and $5 \mathrm{~mm}$ thick

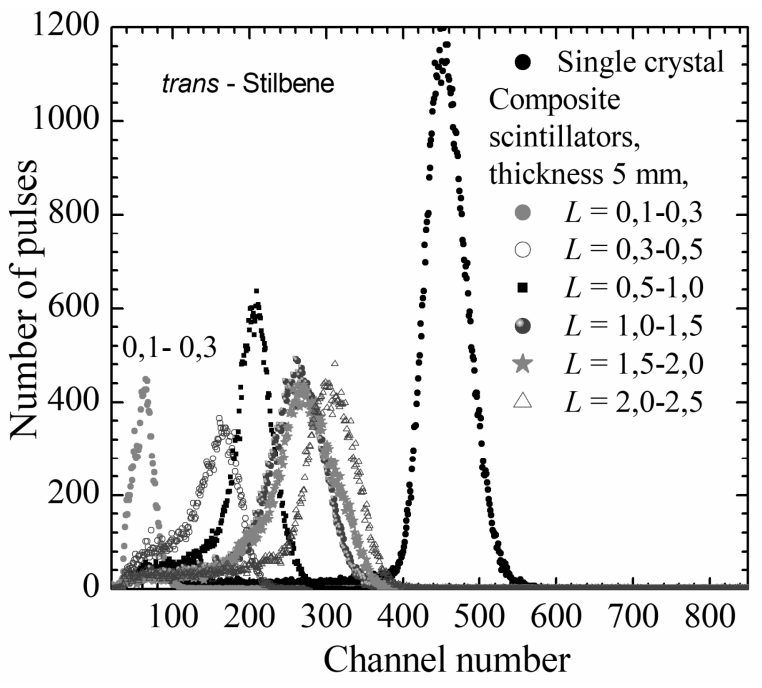

Fig. 3. Spectra of alpha-scintillations of the reference trans-stilbene single crystal and composite scintillators containing trans-stilbene grains of size $L$. Samples thicknesses $5 \mathrm{~mm}$

Table 3

Relative Light output $L_{\text {rel }}$ of composite trans-stilbene scintillators with a thickness of $5 \mathrm{~mm}$

\begin{tabular}{|c|c|c|}
\hline Sample & $\begin{array}{c}\text { Grains size } \\
L, \mathrm{~mm}\end{array}$ & $L_{\text {rel }}, \%$ \\
\hline Single crystal & - & 100.0 \\
\hline Composite scintillator & $0.1 \ldots 0.3$ & 13.3 \\
\hline$-/ /-$ & $0.3 \ldots 0.5$ & 34.9 \\
\hline$-/ /-$ & $0.5 \ldots 1.0$ & 45.6 \\
\hline$-/ /-$ & $1.0 \ldots 1.5$ & 57.1 \\
\hline$-/ /-$ & $1.5 \ldots 2.0$ & 57.6 \\
\hline$-/ /-$ & $2.0 \ldots 2.5$ & 68.2 \\
\hline
\end{tabular}

Table 4 presents $L_{r e l}$ for composite $p$-terphenyl scintillators with a thickness of $5 \mathrm{~mm}$. 


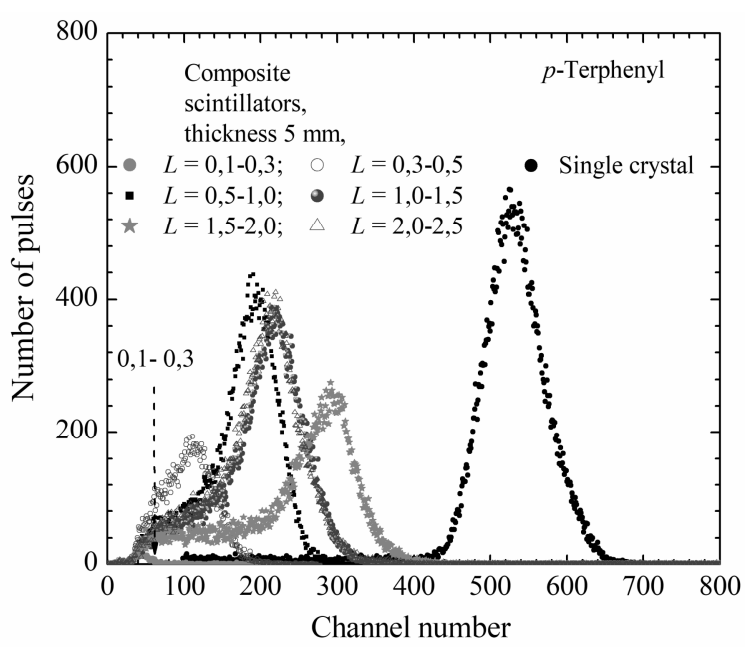

Fig. 4. Spectra of alpha-scintillations of the reference p-terphenyl single crystal and composite scintillators containing p-terphenyl grains of size $L$. Samples thicknesses $5 \mathrm{~mm}$

Table 4

Relative Light output $L_{\text {rel }}$ of composite p-terphenyl scintillators with a thickness of $5 \mathrm{~mm}$

\begin{tabular}{|c|c|c|}
\hline Sample & $\begin{array}{c}\text { Grains size } \\
L, \mathrm{~mm}\end{array}$ & $L_{\text {rel }, \%}$ \\
\hline Single crystal & - & 100.0 \\
\hline Composite scintillator & $0.1 \ldots 0.3$ & 6.9 \\
\hline$-/ /-$ & $0.3 \ldots 0.5$ & 20.5 \\
\hline$-/ /-$ & $0.5 \ldots 1.0$ & 35.9 \\
\hline$-/ /-$ & $1.0 \ldots 1.5$ & 40.3 \\
\hline$-/ /-$ & $1.5 \ldots 2.0$ & 55.3 \\
\hline$-/ /-$ & $2.0 \ldots 2.5$ & 41.5 \\
\hline
\end{tabular}

A study of composite scintillators containing transstilbene or $p$-terphenyl grains, with the thickness equal to a single crystal one, shows the following. For samples with a grain size $L=0.1 \ldots 0.3 \mathrm{~mm}$, the $L_{r e l}$ values are very low (for $p$-terphenyl, the signal practically absent). Based on this, to study radioluminescence, we will use samples that contain crystalline grains with size $L \geq 0.3 \mathrm{~mm}$.

\subsection{OPTICAL TRANSMITTANCE OF COMPOSITE SCINTILLATORS CONTAINING trans-STILBENE OR $p$-TERPHENYL}

We measured optical transmittance $T$ of reference single crystals and composite scintillators $5 \mathrm{~mm}$ thick, containing the trans-stilbene and $p$-terphenyl grains of different sizes. Transmission spectra we measured in the range of light wavelengths $\lambda$ from 200 to $800 \mathrm{~nm}$. Figs. 5 and 6 show the measurement results for samples of trans-stilbene and p-terphenyl, respectively.

Tables 5 and 6 show the values of optical transmittance $T$ of trans-stilbene and $p$-terphenyl single crystals and composite scintillators, containing the grains of these materials, respectively. The measurements we carry out at the wavelength of the maximum of the luminescence spectrum of these materials, i.e., for a light wavelength of $390 \mathrm{~nm}$ [2].

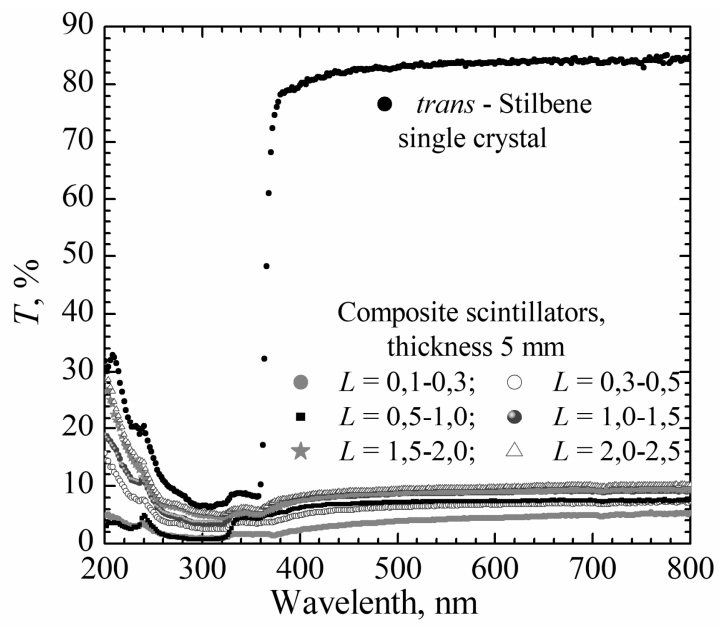

Fig. 5. Optical transmittance spectra of single crystal and composite scintillators of trans-stilbene $5 \mathrm{~mm}$ thick.

The size L of the crystalline grains of the composite samples of trans-stilbene varies

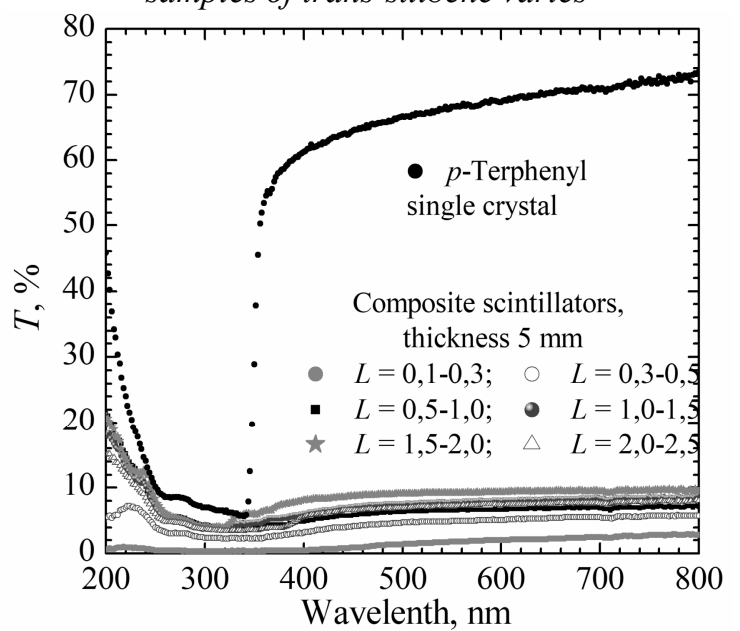

Fig. 6. Optical transmittance spectra of single crystal and composite scintillators of p-terphenyl with a thickness of $5 \mathrm{~mm}$

Table 5

Transmittance T of trans-stilbene composite scintillators $5 \mathrm{~mm}$ thick $(\lambda=390 \mathrm{~nm})$

\begin{tabular}{|c|c|c|}
\hline Sample & Grains size $L, \mathrm{~mm}$ & $T, \%$ \\
\hline Single crystal & - & 78.9 \\
\hline Composite scintillator & $0.1 \ldots 0.3$ & 2.1 \\
\hline$-/ /-$ & $0.3 \ldots 0.5$ & 4.6 \\
\hline$-/ /-$ & $0.5 \ldots 1.0$ & 5.6 \\
\hline$-/ /-$ & $1.0 \ldots 1.5$ & 7.2 \\
\hline$-/ /-$ & $1.5 \ldots 2.0$ & 7.1 \\
\hline$-/ /-$ & $2.0 \ldots 2.5$ & 7.9 \\
\hline
\end{tabular}

Table 6

Transmittance $T$ of p-terphenyl composite scintillators $5 \mathrm{~mm}$ thick $(\lambda=390 \mathrm{~nm})$

\begin{tabular}{|c|c|c|}
\hline Sample & Grains size $L, \mathrm{~mm}$ & $T, \%$ \\
\hline Single crystal & - & 60.1 \\
\hline Composite scintillator & $0.1 \ldots 0.3$ & 0.5 \\
\hline$-/ /-$ & $0.3 \ldots 0.5$ & 3.0 \\
\hline$-/ /-$ & $0.5 \ldots 1.0$ & 4.6 \\
\hline$-/ /-$ & $1.0 \ldots 1.5$ & 5.6 \\
\hline$-/ /-$ & $1.5 \ldots 2.0$ & 7.8 \\
\hline$-/ /-$ & $2.0 \ldots 2.5$ & 4.7 \\
\hline
\end{tabular}




\section{CONCLUSIONS}

The results of studies of single-layer composite scintillators with a grain size $L$ of up to $0.06 \ldots 0.1 \mathrm{~mm}$ show that the light output of samples drops sharply with $L$. The use of composite scintillators containing grains of trans-stilbene and $p$-terphenyl with fewer $L$ values for the detection of ionizing radiation is meaningless. In other words, the use of scintillators containing grains with $L$ less than $0.1 \mathrm{~mm}$ when excited by ionizing radiation is impractical.

The higher $L_{r e l}$ value for single-layer composite scintillators, with the same thicker as the reference single crystal, is explained by two reasons. First, for a thinner object, the transmittance is higher. The second reason (and it is the main one) is related to the specificity of light collection in transparent samples. There is practically no light scattering in such objects, and, therefore, there is no displacement of the trajectories of light rays (no mixing of trajectories). Incidence angles for all surfaces are preserved, and the sample effectively captures light with large initial incidence angles. We previously observed this effect for thin samples of trans-stilbene and $p$-terphenyl [2].

The results of studies of composite scintillators containing grains of trans-stilbene and p-terphenyl (see Figs. 3, 4, Tables 3 and 4) with a thickness equal to the thickness of the single crystals showed that for samples with a grain size $L=0.1 \ldots 0.3 \mathrm{~mm}$. The values of the relative light output $L_{r e l}$ are very low (there is practically no signal for $p$-terphenyl). Therefore, to study radioluminescence, one should use samples containing crystal grains with $L \geq 0.3 \mathrm{~mm}$.

\section{ACKNOWLEDGEMENTS}

This work was supported by the National Research Foundation of Ukraine (project No. 2020.01/0133, "Heterostructured organic scintillators with high pulse shape discrimination capability for radioecology problems").

\section{REFERENCES}

1. The 2007 Recommendations of the International Commission on Radiological Protection. Publication 103 // Annals of the ICRP. 2007, № 37, p. 1-332.
2. N.Z. Galunov, V.P. Seminozenko. Radioluminescencia organiceskih kondensirovannyh sred. Teoria i primenenie. Kiev: «Naukova dumka», 2015.

3. S.V. Budakovsky, N.Z. Galunov, N.L. Karavaeva, et al. New Effective Organic Scintillators for Fast Neutron and Short-Range Radiation Detection // IEEE Trans. Nucl. Sci. 2007, v. 54, p. 2734-2740.

4. O. Tarasenko, N. Galunov, N. Karavaeva, I. Lazarev. Stilbene composite scintillators as detectors of fast neutrons emitted by a ${ }^{252} \mathrm{Cf}$ source // Radiat. Meas. 2013, v. 58, p. 61-65.

5. N.L. Karavaeva. Composite scintillators as new type of a scintillation material // Problems of Atomic Science and Technology. Series "Nuclear Physics Investigations”. 2014, № 5, p. 91-97.

6. N.Z. Galunov, N.L. Karavaeva, O.A. Tarasenko. Crystalline and Composite Scintillators for Fast and Thermal Neutron Detection // Engineering of Scintillation Materials and Radiation Technologies / Ed by Mikhail Korzik and Alexander Gektin: Springer Proceedings in Physics. 2017, v. 200, p. 199-212.

7. N.Z. Galunov, I.F. Khromiuk, O.A. Tarasenko. Features of pulse shape discrimination capability of organic heterogeneous scintillators // Nuclear Inst. and Methods in Physics Research A. 2020, v. A 949, p. 162870.

8. N. Galunov, D. Gryn, N. Karavaeva, et al. Delayed radioluminescence of some heterostructured organic scintillators // Journal of Luminescence. 2020, v. 226, p. 117477 .

9. N. Zaitseva, A. Glenn, L. Carman et al. Scintillation properties of solution-grown trans-stilbene single crystals // Nucl. Instrum. Meth. Phys. Res. A. 2015, v. 789 , p. 8-15.

10. N.Z. Galunov, O.A. Tarasenko, V.A. Tarasov. Determination of the Light output of organic scintillators // Functional materials. 2013, v. 20, p. 304-309.

11. Shimadzu UV-VIS spectrophotometers. UV-2450, UV-2550. Available: https://www.ssi.shimadzu. com/products/literature/spectroscopy/uv24502550.pdf

Article received 14.04.2021

\title{
ГЕТЕРОСТРУКТУРИРОВАННЫЕ ОРГАНИЧЕСКИЕ СЦИНТИЛЛЯТОРЫ С ВЫСОКОЙ СПОСОБНОСТЬЮ К РАЗДЕЛЕНИЮ ИОНИЗИРУЮЩЕГО ИЗЛУЧЕНИЯ ПО ФОРМЕ СЦИНТИЛЛЯЦИОННОГО ИМПУЛЬСА ДЛЯ ЗАДАЧ РАДИОЭКОЛОГИИ
}

\author{
И.Ф. Хромюк, Н.З. Галунов, Н.Л. Караваева, А.В. Креч, Я.И. Полупан, О.А. Тарасенко
}

Проведены исследования относительного светового выхода и оптического пропускания органических композитных сцинтилляторов с различным размером гранул. Результаты исследований показали, что для образцов с фракцией гранул $0,06 \ldots 0,3$ мм, в отличие от образцов с крупными гранулами, относительный световой выход и оптическое пропускание крайне низки.

\section{ГЕТЕРОСТРУКТУРОВАНІ ОРГАНІЧНІ СЦИНТИЛЯТОРИ З ВИСОКОЮ ЗДАТНІСТЮ ДО РОЗДІЛЕННЯ ІОНІЗУЮЧОГО ВИПРОМІНЮВАННЯ ЗА ФОРМОЮ СЦИНТИЛЯЦИЙНОГО ІМПУЛЬСУ ДЛЯ ЗАДАЧ РАДІОЕКОЛОГІЇ}

\section{І.Ф. Хромюк, М.З. Галунов, Н.Л. Караваєва, А.В. Креч, Я.І. Полупан, О.А. Тарасенко}

Проведено дослідження відносного світлового виходу і оптичного пропускання органічних композитних сцинтиляторів з різним розміром гранул. Результати досліджень показали, що для зразків з фракцією гранул 0,06...0,3 мм, на відміну від зразків з гранулами більшого розміру, відносний світловий вихід і оптичне пропускання є вкрай низькими. 